relative efficacy of two screening procedures, and the curve provides a rational estimate of the threshold to be used in a given setting since one can see the best trade off between sensitivity and specificity. This threshold is then used to calculate the predicted prevalence of disorder and positive and negative predictive values.

It is necessary to use a stratified sampling strategy only if the prevalence of disorder is below $40 \%$, to avoid spending too much time interviewing non-cases. If this is done, however, it is essential to weight the data back to the original sample of consecutive subjects; otherwise the estimate of specificity will be too low and the estimate of sensitivity will be too high.

It is advisable to calculate an ROC curve to check that the threshold chosen is appropriate: in medical and neurological inpatients, for example, the threshold may have to be raised as high as $9 / 10$ on the general health questionnaire- 28 to take account of symptoms and social dysfunction produced by medical illness.

Professor of Psychiatry,

DAVID GOLDBERG

University of Manchester,

Withington Hospital,

Manchester M20 8LR

1 Nabarro J. Unrecognised psychiatric illness in medical patients. Br Med f 1984;289:635-6. 2 Goldberg $\mathrm{D}$. The recognition of psychiatric illness by non-psychiatrists. Aust $N Z \mathcal{F}$ Psychiatry 1984;18:128-34.

3 Vazquez-Barquero JL. Padierna Acero JA, Pena Martin C, Ochoteco A. The psychiatric correlates of coronary pathology: validity of the GHQ-60 as a screening instrument. Psychol Med 1985; 15:597-608

4 Goldberg D, Blackwell B. Psychiatric illness in general practice. Br Med f 1970;ii:439-43.

5 Goldberg D. Manual of the general health questionnaire. Windsor: NFER, 1978.

6 Bridges K, Goldberg D. Psychiatric illness in patients with neurological disorders. Br Med $\mathcal{J}$ I984;288:268-71.

Goldberg $\mathrm{D}$. Estimating the prevalence of a disorder from the results of a screening test. In: Wing JK, Bebington P, Robins L, eds. What is a case? London: Grant McIntyre, 1981:129-36. 8 Goldberg D. Identifying psychiatric illness among general medical patients. Br Med $f$ 1985;291:161-2.

Wing JK, Mann SA, Leff JT, Nixon JN. The concept of a case in population studies. Psychol Med 1978;8:203-19.

10 Goldberg DP, Cooper AB, Eastwood MR, Kedward HB, Shepherd M. A psychiatric interview suitable for use in community surveys. British foumal of Preventive and Social Medicine 1970;24:18-26.

11 American Psychiatric Association. Diagnostic and statistical manual-III-R. Washington: American Psychiatric Association, 1985

12 Metz CE. Basic principles of ROC analysis. Semin Nucl Med 1978;8:283-98.

13 Hanley JA, McNeil BJ. The meaning and use of the area under the ROC curve. Radiology 1982;143:29-36.

14 Mari JJ, Williams P. A comparison of the validity of two psychiatric screening questionnaires in Brazil using ROC analysis. Psychol Med 1985;15:651-9.

\section{Subnutrition in the elderly}

Because of widespread concern about the poor nutritional state of some elderly people several large community studies were done in the 1960s and 1970s; these showed that most elderly people had an adequate diet..$^{1-6}$ About $1-2 \%$ of those surveyed were, however, suffering from serious subnutrition. This means about 200000 people in Britain, and doctors need to know how to identify subnutrition and which groups are most at risk.

Most at risk are people with severe mental or physical incapacity. Social isolation is a risk factor only if compounded by ill health, and, indeed, old women living alone eat rather better than those living with others. ${ }^{6}$ Poverty does not appear to be a factor, though old people on low incomes may have to choose between feeding and heating themselves. Ignorance over entitlement to supplementary benefits is often at the root of this difficulty.

Identifying subnutrition is difficult. Accurate information on dietary intake requires a skilled dietitian and a cooperative subject who is prepared to weigh her intake of foodstuffs over a whole week. There are various shortcuts in which the dietitian uses a questionnaire, but it is usually patients who are most at risk who are least able to provide the necessary information. Doctors may thus have to resort to measuring the clinical and biochemical consequences of subnutrition, but these may present difficulties. Old people often exhibit classical signs of nutrient deficiency (angular stomatitis, glossitis, or peripheral oedema), but these are usually the result of intercurrent illness. ${ }^{7}$ Many old people have low serum vitamin concentrations, ${ }^{189}$ but these simply reflect increased physiological and biochemical variation in old age-for example, low riboflavine or calcifediol (25-hydroxycholecalciferol) concentrations are not necessarily associated with clinical abnormalities. ${ }^{10}$

Attempts have recently been made to produce order out of chaos by standardising anthropometric and biochemical data in the elderly and resting their reliability in distinguishing between normality and subnutrition..$^{11-13}$ Easily measured and calculated values such as the triceps skinfold thickness, arm muscle area, and corrected arm muscle area are useful in assessing nutritional state. Serum albumin and prealbumin concentrations may also help, though in some groups acute illness seems to be more important than dietary deficiency in reducing these. ${ }^{13}$

Even if subnutrition can be identified there is uncertainty as to its effect on the health of old people-for example, vitamin $\mathrm{D}$ deficiency may cause a proximal myopathy, but calciferol supplements do not seem to improve mobility in most old people with low serum calcifediol concentrations. ${ }^{14}$ Folic acid deficiency may cause mental impairment and folate concentrations are often low in patients with dementia -yet folate supplements are of little benefit in most of them. ${ }^{15}$ Nutrient correction may, however, be of considerable value: ascorbic acid accelerates the healing of surgical wounds and pressure sores while calciferol is vital for frank osteomalacia. ${ }^{16} 17$

Clinical and biochemical indices of subnutrition are associated with acute illness and an increased mortality, ${ }^{18}$ but are they cause or effect? Stress pushes old people into negative nitrogen balance, while acute infections alter the ratio of buffy coat to plasma ascorbic acid. ${ }^{19}$

Since only a minority of old people suffer from subnutrition, the first step is to identify those at risk. This is the task for the primary care team supported wherever possible by a health visitor or geriatric visitor. Thereafter the dietitian may have a part to play in providing advice and designing and distributing booklets. ${ }^{20}$ This is most easily organised in day centres, lunch clubs, and day hospitals.

The time honoured system for supplementing the diet of an elderly patient is to organise a meals on wheels service, but are these effective? Individual meals will appreciably improve the diet only if served at least four times a week, and there are also problems such as loss of nutrient value during distribution and ensuring that meals are actually eaten..$^{21}$ Meals served at luncheon clubs, day centres, and day hospitals are more likely to be effective because they are eaten with others. Relatives should also be given advice from a dietitian or health visitor on specific nutritional problems that arise.

The use of nutrient supplements is controversial. There is little evidence that their routine use is of much value in the elderly, but individuals with specific problems may be helped-for example, patients with biochemical evidence of osteomalacia should be given calciferol (as a large single parenteral or oral dose once every six months ${ }^{1022}$ ). The injection of $\mathrm{B}$ complex vitamins may be useful in managing confusional states in acute illness or after a proximal fracture 
of the femur, circumstances in which thiamine deficiency is common. ${ }^{23}$ Protein supplements have also been given down nasogastric tubes to counteract the catabolic effects of trauma in hip fractures. ${ }^{24}$ Whether this approach may also benefit the many cachectic and acutely ill elderly patients who present to geriatric and general medical units remains to be seen.

Professor of Geriatric Medicine,

W J MACLENNAN

City Hospital, Edinburgh EH10 5SB

1 Department of Health and Social Security. A nutrition survey of the elderly. London: HMSO, 1972. (Reports on Public Health and Medical Subjects No 3.)

2 MacLeod CC, Judge TG, Caird FI. Nutrition of the elderly at home. I. Intakes of energy, proteins, carbohydrates and fat. Age Ageing 1974;3:158-68.

3 MacLeod CC, Judge TG, Caird FI. Nutrition of the elderly at home. II. Intakes of vitamins. Age Ageing 1974;3:209-20.

4 MacLeod CC, Judge TG, Caird FI. Nutrition of the elderly at home. III. Intakes of minerals. Age Ageing 1975;4:49-57.

Lonergan ME, Milne JS, Maule MM, et al. A dietary survey of older people in Edinburgh. Br $\mathcal{J}$ Nutr 1975;34:417-27.

6 Department of Health and Social Security. Nutrition and health in old age. London: HMSO, 1979. (Reports on Health and Social Subjects No 16.)

7 MacLennan WJ. Clinical assessment of nutritional status in the elderly. In: Kemm JR, ed. MacLennan WJ. Clinical assessment of nutritional status in the elderly.
Vitamin deficiency in the elderly. Oxford: Blackwell Scientific, 1985: 22-45.

8 Milne JS, Lonergan ME, Williamson J, et al. Leucocyte ascorbic acid levels and vitamin C intake Milne JS, Lonergan ME, Williamson J, et
in older people. Br Med f 1971;iv:83-6.

9 MacLennan WJ, Hamilton JC, Timothy JI. 25-Hydroxy-vitamin D concentrations in old people living at home. Foumal of Clinical and Experimental Gerontology 1979;1:201-15.

10 Burns J, Davidson AV, MacLennan WJ, Paterson CR. The value of serum 25-hydroxy-vitamin D assays in screening elderly patients for vitamin D deficiency. Fournal of Clinical and Experimental Gerontology 1985;7:213-22.

$11 \mathrm{Kemm}$ JR, Allcock J. The distribution of supposed indicators of nutritional status in elderly patients. Age Ageing 1984;13:21-8.

12 Morgan DB, Newton HMV, Schorah CJ, et al. Abnormal indices of nutrition in the elderly: a study of different clinical groups. Age Ageing 1986;15:65-76.

13 Friedman PJ, Campbell AJ, Caradoc-Davies TH. Hypoalbuminemia in the elderly is due to disease not malnutrition. Foumal of Clinical and Experimental Gerontology 1985;7:191-204.

14 Corless D, Dawson E, Fraser F, et al. Do vitamin supplements improve the physical capabilities of elderly hospital patients? Age Ageing 1985;14:76-84.

elderly hospital patients? Age Ageing 1985;14:76-84.
15 Shaw DM, MacSweeney DA, Johnson AL, et al. Folate and amine metabolites in senile dementia: Shaw DM, MacSweeney DA, Johnson AL, et al. Folate and amine me

a combined trial and biochemical study. Psychol Med $1971 ; 1: 166-71$.
16 Taylor TV, Dymock IW, Torrance B. The role of vitamin C in the treatment of pressure sores in Taylor TV, Dymock IW, Torrance B. The
surgical patients. Brf Surg 1974:6:921.

17 Burns J, Paterson CR. Single dose vitamin D treatment for osteomalacia in the elderly. Br Med $\mathcal{F}$ 1985;290:281-2.

18 Phillips $P$. Grip strength, mental performance and nutritional status as indicators of mortality risk among female geriatric patients. Age Ageing 1986;15:53-6.

9 MacLennan WJ, Hamilton JC. The effect of acute illness on leucocyte and plasma ascorbic acid levels. Br F Nutr 1977;38:217-23.

20 Henderson J. Nutritional advice for the elderly. In: Caird FI, Evans JG, eds. Advanced geriatric medicine 3. London; Pitman, 1983: 29-35.

21 Exton-Smith AN, Stanton BR. Report of an investigation into the dietary of elderly women living alone. London: King Edward's Hospital Fund, 1965.

22 Davies M, Mairen EB, Hann TJ, et al. Vitamin D prophylaxis in the elderly: a simple effective method suitable for large populations. Age Ageing 1985;14:349-54.

23 Older MWJ, Dickerson JWT. Thiamine and the elderly orthopaedic patient. Age Ageing 1982;11:101-7.

24 Bastow MD, Rawlings J, Allison SP. Benefits of supplementary tube feeding after fractured neck of femur: a randomised controlled trial. Br Med J 1983;287:1589-92.

\section{Reviving the Commonwealth Medical Association}

When the BMA withdrew from the World Medical Association in $1984^{1}$ it was left with two regular international commitments: the Standing Committee of Doctors of the European Community and the Commonwealth Medical Association. The former, of which the BMA has always been an active member, is influential on the European medical scene. The latter could be an influential body in international medicine. Sadly the CMA is in no shape to do this at present, as the recent biennial council meeting held in Cyprus showed.

In politics an organisation with only seven participating members out of a potential membership of 49 carries little clout. Indeed, it was thanks only to the generosity and efforts of the Pancyprian Medical Association, coupled with the BMA's provision of limited secretarial services for the past two years, that the 1986 meeting took place at all. Not surprisingly the delegates present-representing Cyprus,
India, Jamaica, Fiji, Trinidad and Tobago, and the United Kingdom-led by the president, Dr N K Tong from 3

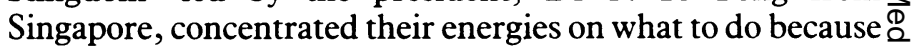
all agreed that unless the association could be reinvigorated it $C$ would fade into history.

When the BMA led in launching the CMA in the early 1960s the following aims and objectives were agreed: to promote within the Commonwealth the medical and allied $m$ sciences and to maintain the honour of the profession; to? effect the closest possible links between members; and to $\underset{\vec{\rho}}{\vec{\rho}}$ disseminate news and information of interest.

Though these general aims have been largely unfulfilled $\frac{\text { c }}{5}$ they remain valid today. Only if they can be translated into $\overline{\frac{\bar{s}}{2}}$ action, however, will a majority of Commonwealth medical $\mathbb{\otimes}$ associations join, pay their subscriptions, and contribute to the CMA's operation. A lifeline was offered by the BMA and ${ }_{\overrightarrow{0}}^{\infty}$ gladly accepted by the meeting: it will provide the secretariat ${ }_{-}^{\circ}$ for the CMA; it will promote the programme of work $\vec{\omega}$ approved by the CMA's council; it will encourage national $\frac{}{\circ}$ medical associations to join; and it will seek additional 3 . sources of finance. If, however, within two years the response iु to this initiative is inadequate the BMA will relinquish the secretariat.

This offer puts considerable responsibility on the کु BMA. An early target will be to persuade inactive members $\vec{\overrightarrow{ }}$ such as Nigeria and Kenya to take part and the wealthier $\stackrel{\infty}{\bullet}$ associations such as the Australians and Canadians to rejoin, 음 as their presence will be essential to boost the CMA's $\infty$ credibility and finances. The BMA's senior officers, who $Z$ attended the Cyprus meeting, hope that opportunities will arise for personal approaches to these countries' associations. More difficult will be those smaller Commonwealth associa- $\stackrel{\Phi}{-}$ tions which do not always reply to letters of inquiry. $\vec{\varphi}$ Communications will be improved, however, as the BMA is planning to launch a quarterly CMA bulletin.

Attracting external funds will likewise be hard. The Commonwealth Foundation withdrew its help some time ago and would doubtless be reluctant to restart unless the CMA could prove it was working effectively. But private philan- $\stackrel{\mathbb{Q}}{\varrho}$ thropic foundations might be willing to consider help, and $\overrightarrow{\vec{O}}$ the pharmaceutical industry and private health corporations 3 are other possible sources of funds. To convince them and Commonwealth doctors of its usefulness, firstly, the CMA must strengthen its link with the triennial conference of the Commonwealth health ministers, at which it has observer status. Secondly, the CMA must explore ways of linking with $\frac{5}{3}$ the World Health Organisation. Thirdly, it should be a source of advice for national medical associations-for $\frac{\circ}{3}$ example, on ethics, health care financing, and particular national medical difficulties. This year, for instance, the $\underset{\sim}{\supset}$ CMA supported a call from the Pancyprian Medical Associa- of tion to allow patients throughout divided Cyprus access $\frac{D}{0}$ to doctors of their choice. Fourthly, its regular council meetings should be linked with a self financing international $N$ conference-perhaps with another profession—on subjects $\omega$ of common professional interest-for example, the quality of drugs, alcoholism, and medicolegal dilemmas. Such a con- $\frac{0}{\Phi}$ ference is planned for London in 1989.

All this is a tall order, but the BMA has the knowledge and the experience to relaunch the CMA towards these targets. A $\stackrel{\circ}{\circ}$

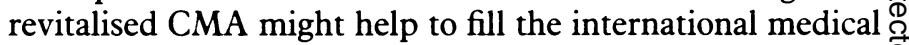
role that a lame duck World Medical Association is signally $\stackrel{\mathbb{D}}{\varrho}$ failing to do.

Deputy Editor, $B M \mathcal{F}$.

GORDON MACPHERSON o 